\title{
THYROID FUNCTION DISORDERS IN LOW BIRTH WEIGHT/ PRETERM NEONATES ADMITTED IN NICU, CHILDREN HOSPITAL COMPLEX MULTAN.
}

1. MBBS, DCH, FCPS (Pediatrics) FCPS (Neonatology)

Assistant Professor Neonatology Children Hospital and Institute of Child Health, Multan.

2. MBBS, FCPS (Paediatrics)

Fellowship in Paediatrics

Endocrinology

Associate Professor Endocrinology

Children Hospital and Institute of

Child Health, Multan.

3. MBBS, FCPS (Pediatrics)

Assistant Professor

Bakhtawar Ameen Medical and Dental College Multan

4. MBBS, MCP

Admin Registrar Neonatology

Children Hospital and Institute of

Child Health, Multan.

5. MBBS, FCPS (Pediatrics)

Head of Paediatrics

Children Hospital and Institute of

Child Health, Multan.

Correspondence Address:

Dr. Abdur Rehman

Al-Rahim Colony Prince Hotel Street

Nishtar Road Near Nishtar Flyover

Multan.

dr.armalik@outlook.com

Article received on:

06/12/2019

Accepted for publication:

04/03/2020

\begin{abstract}
Abdur Rehman ${ }^{1}$, Waqas Imran Khan ${ }^{2}$, Ahmed Iqbal Quddusi ${ }^{3}$, Ashee Nadeem ${ }^{4}$, Imran Iqbal ${ }^{5}$
\end{abstract}
ABSTRACT... Objectives: Congenital hypothyroidism (CHT) is one of the major endocrine and metabolic disorders in neonates. Delayed diagnosis and treatment of $\mathrm{CHT}$ may lead to certain neuro-developmental disorders. Study Design: Prospective study. Setting: NICU of Children Hospital, Institute of Child Health Multan, Pakistan. Period: September 2018 to November 2019. Material \& Methods: A total of 142 neonates of both gender having birth weight of less than 1500 grams were enrolled in this study. Thyroid function tests, like TSH, free T4 and T4 levels were performed in all these neonates between $1-5^{\text {th }}$ day, $2^{\text {nd }}$ week and $4^{\text {th }}$ week of life by radioimmunoassay. Results: Out of 142 neonates, 76 (53.5\%) were male and 66 (46.5\%) female. Mean gestational age was $31.41 \pm 1.93$ weeks while mean birth weight was found to be $1261.53+170.36$ grams. Gestational age of $<28$ weeks was noted in $9(6.3 \%)$ neonates, 28 to $<30$ weeks in 59 (40.4\%), 30 to 32 weeks in $33(23.2 \%)$ and 41 (28.9\%) were above 32 weeks. Thyroid function disorders were noted in $89(62.7 \%)$ neonates while transient hypothyroxinemia was the most common one, found in $65(45.7 \%)$ neonates, transient hyperthyroxinemia in 12 (8.4\%) and Congenital hypothyroidism (CHT) in 12 (8.4\%). Nasal continuous positive airway pressure (NCPAP) was used for treating respiratory distress syndrome (RDS) in 107 (75.4\%) neonates. Surfactant administration was done in 69 (48.6\%). Patent ductus arteriosis (PDA) was noted in 27 (19.0\%), intraventricular hemorrhage (IVH) in 8 (5.6\%) and culture proven sepsis was seen in $18(12.7 \%)$. Conclusion: In low birth weight / preterm neonates, thyroid function disorders are quite common. Transient Hypothyroxinemia was noted to be the most common disorder and congenital hypothyroidism was present in $8.4 \%$ of neonates.

Key words: Congenital Hypothyroidism, Thyroid Function Disorder, Transient Hypothyroxinemia.

Article Citation: Rehman A, Khan WI, Quddusi AA, Nadeem A, Iqbal I. Thyroid function disorders in low birth weight/preterm neonates admitted in NICU, Children Hospital Complex Multan. Professional Med J 2020; $27(8): 1649-1655$. DOI: 10.29309/TPMJ/2020.27.08.4398

\section{INTRODUCTION}

Congenital hypothyroidism (CHT) is known to be one of the major endocrine and metabolic disorders. Amongst neonates, delay in the diagnosis and treatment of $\mathrm{CHT}$ may result in neuro-developmental disorders. ${ }^{1}$ Frequency of $\mathrm{CHT}$ is noted as 1 per 3500 infants. $^{2}$ In regional findings, $\mathrm{CHT}$ was noted to be present in $2 \%$ infants. $^{3}$ Most of the neonates having $\mathrm{CHT}$ exhibit very few symptoms, in fact, many stay asymptomatic. In these cases, progression of CHT may take months to become symptomatic. ${ }^{4}$

Proper functioning of thyroid gland is very important for brain to develop normally in infants and in the form of delayed diagnosis, chances of developing serious mental complications are increased. ${ }^{5}$ Within half an hour to one hour following delivery, surge in serum thyroid stimulating hormone is seen as up to levels of 60 to $80 \mathrm{mU} / \mathrm{L}$, depending upon environmental temperature as well as umbilical cord clamping. These levels fall down to $20 \mathrm{mU} / \mathrm{L}$ within 1 day following birth and then goes on to 6 to $8 \mathrm{mU} / \mathrm{L}$ during $1^{\text {st }}$ week. The $1^{\text {st }}$ surge in TSH levels result in stimulating secretions of $\mathrm{T} 4$ along with exchange of T4 to T3. 6,7

In infants those are premature, T4 and free T4 levels are interrelated with birth weight as well as gestational age. As per previous researches, mean T4 serum levels in extremely low birth 
weight (ELBW) infants is $5.6 \mathrm{mcg} / \mathrm{dL}$ after 2 to 5 days following birth, whereas it was noted as a mean of $6.7 \mathrm{mcg} / \mathrm{dL}$ in those infants who were < 30 weeks of gestational age. Mean free T4 levels of $1.2 \mathrm{ng} / \mathrm{dL}$ have been noted in infants $<30$ weeks of gestational age..$^{8,9}$

In the post-natal period, it has been observed that levels of TSH, T3 and T4 become quite alike to term infants. In comparison to term neonates, in premature newborns, thyroid hormone levels may fall because of immaturity of the thyroid gland, but these changes may be exacerbated by complications of prematurity. Thyroid metabolism can by affected by exogenous sources of iodine, dopamine infusions, blood transfusion and glucocorticoid treatment. ${ }^{10}$

Taking into consideration the abnormalities in some thyroid hormonal levels amongst premature infants, these infants are more prone to thyroid disorders like transient hypothyroxinemia, neonatal hypothyroidism and transient hyperthyroxinemia. ${ }^{11-13}$ Our setting being the most common tertiary care center in the south Punjab region, no study has been done to find out the status of thyroid function disorders in neonates admitted in the neonatal intensive care unit (NICU). So, aim of this study was to find out thyroid function disorders in neonates coming to us and admitted in NICU with birth weight $<1500$ grams. Neonatal screening can provide early diagnosis and can prevent delays in treatment.

\section{MATERIAL \& METHODS}

This was a prospective study, conducted at NICU of Children Hospital, Institute of Child Health Multan, Pakistan from September 2018 to November 2019. A total of 142 neonates of both gender and having birth weight of less than 1500 grams were enrolled in this study. All those neonates were not enrolled who had any major congenital abnormality, blood exchange transfusion or mortality in $1^{\text {st }}$ month of life.

Approval from institutional ethical committee was sought for this research. Informed consent was acquired from parents or guardians of all the study participants. Thyroid function tests, like
$\mathrm{TSH}$, free T4 and T4 levels were performed in all these neonate in between $1-5^{\text {th }}$ day, $14^{\text {th }}$ day and 4th week of life with radioimmunoassay. Blood samples of 1 to $1.5 \mathrm{cc}$ were taken from forearms of the study participants and all investigations were analyzed at institutional laboratory. Thyroid function abnormalities were labeled on the bases of figures given in Figure-1 and Figure-2 and according to thyroid dysfunction definitions. . $^{6,14}$

Diagnosis of transient hypothyroxinemia was made as low T4 and free T4 levels as well as normal levels of TSH. Diagnosis as neonatal hypothyroidism was made as raised levels of TSH and decreased free T4 and T4 levels during the neonatal period. Diagnosis as transient primary neonatal hypothyroidism was made as decreased or consistently lowering levels of free T4 while moderate raise of TSH levels. Diagnosis as hyperthyroxinemia was made as raised levels of TSH during neonatal period even if T4 and free T4 levels were found to be normal. ${ }^{6,14}$

SPSS version 21.0 was used for data handling and analysis. Quantitative variables were presented as mean and standard deviation (SD) while qualitative variables were represented in the shape of frequency and percentages. Chi square test and independent sample t test was used to for comparisons in between neonates, and $p$ value less than or equal to 0.5 was taken as statistically significant.

\section{RESULTS}

Out of a total of 142 neonates, 76 (53.5\%) were male and 66 (46.5\%) female. Mean gestational age was $31.41 \pm 1.93$ weeks while mean birth weight on $5^{\text {th }}$ day was found to be $1261.53+$ 170.36 grams. Gestational age $<28$ weeks was noted in $9(6.3 \%)$ neonates, 28 to 30 in 59 $(40.4 \%),>30$ to 32 weeks in $33(23.2 \%)$ and 41 (28.9\%) above 32 weeks. Table-I

Some of the cases got excluded because of reasons like lack of compliance and adherence to study protocols. Evaluation of 131 infants was done at 2 weeks and 117 infants got evaluated on $4^{\text {th }}$ week. Ninety eight neonates completed the study at 6 weeks interval of the study. 


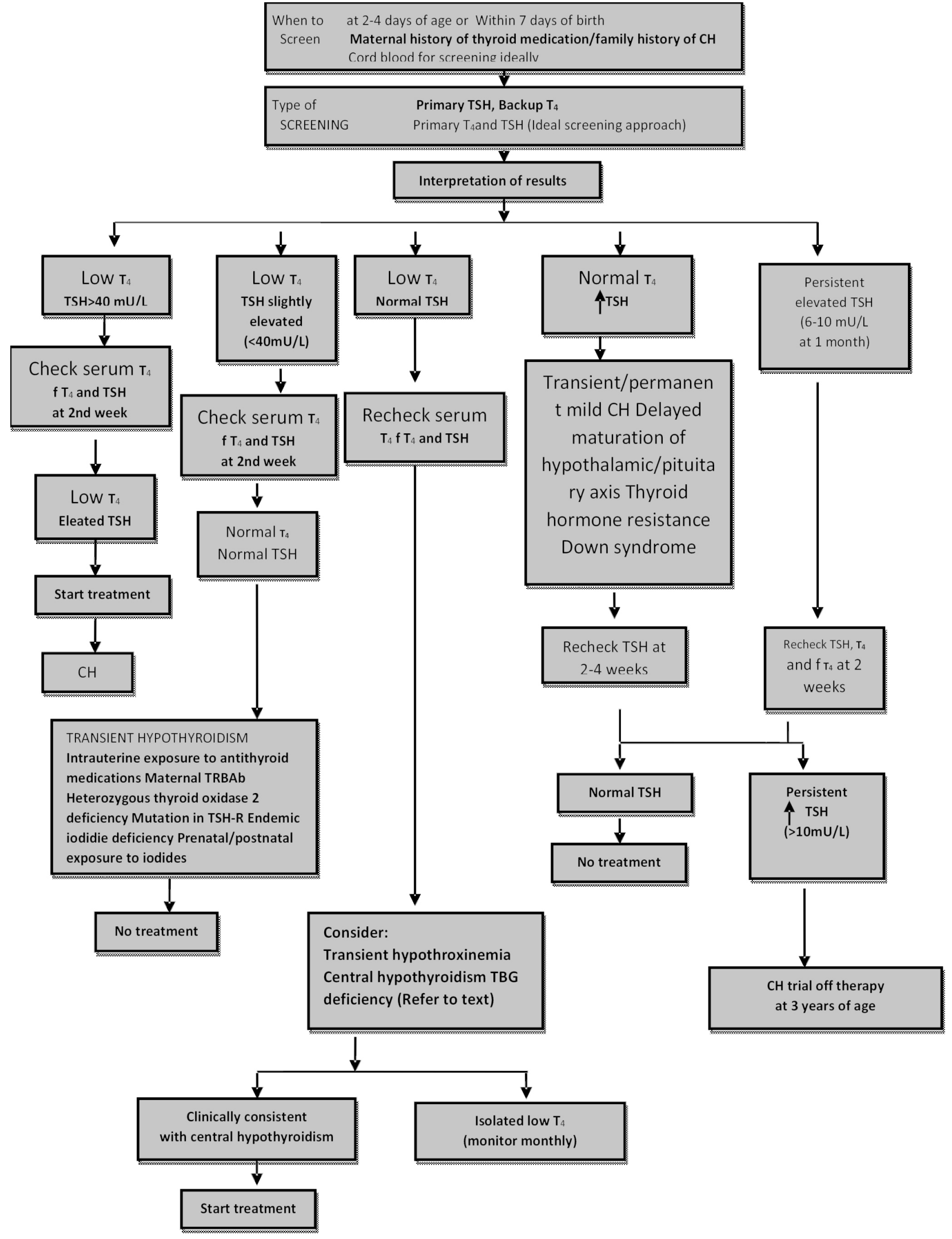

Algorithm for evaluating congential hypothyroidism (CH) 
Table-Il shows that TSH, free T4 and T4 levels increased with increasing gestational age while Table-III is showing mean values of T4, Free T4 and $\mathrm{TSH}$ at different study intervals.

Thyroid function disorderswerenoted in 89 (62.7\%) neonates while transient hypothyroxinemia was shown to be the commonest, found in 52 (36.6\%), transient primary neonatal hypothyroidism in $13(9.2 \%)$, transient hyperthyrotropinemia in 12 (8.4\%) and $\mathrm{CHT}$ in 12 (8.4\%).
(NCPAP) was used for treating respiratory distress syndrome (RDS) in 107 (75.4\%) neonates. Surfactant administration was done in 69 (48.6\%). Patent ductus arteriosis (PDA) was noted in 27 (19.0\%), intraventricular hemorrhage (IVH) in 8 (5.6\%) and clinical sepsis was seen in 18 (12.7\%).

Table-IV shows that when neonates having thyroid function disorders were compared with those having no thyroid function disorders for clinical status found, no significance was noted in between the neonates ( $p$ value $>0.05$ ).

Nasal continuous positive airway pressure

\begin{tabular}{|c|c|c|c|c|}
\hline Age of Specimen & Gestational Age (Weeks) & Free T4 (ng/dl) & T4 (mcg/dl) & TSH (mu/L) \\
\hline week 1 & \multirow{3}{*}{$<28$ weeks } & $1.29+/-0.5$ & $3.8+/-1.7$ & $3.3+/-2.1$ \\
\hline Week 2 & & $1.31+/-0.3$ & $4.2+/-2.4$ & $4+/-2.2$ \\
\hline Week 4 & & $1.49+/-0.2$ & $5.9+/-2.6$ & $3.5+/-2.1$ \\
\hline week 1 & \multirow{3}{*}{ 28- $<30$ Weeks } & $1.81+/-0.6$ & $6.3+/-2.1$ & $3.5+/-2.2$ \\
\hline Week 2 & & $1.62+/-0.3$ & $6.6+/-2.3$ & $4.8+/-10.8$ \\
\hline Week 4 & & $1.71+/-0.2$ & $7.5+/-2.1$ & $3.6+/-2.4$ \\
\hline week 1 & \multirow{3}{*}{30 - 32 Weeks } & $2.14+/-0.6$ & $9.4+/-3.2$ & $3.6+/-3.8$ \\
\hline Week 2 & & $2.10+/-0.4$ & $9.6+/-3.6$ & $3.9+/-10.1$ \\
\hline Week 4 & & $1.88+/-0.5$ & $8.9+/-2$ & $3.5+/-3.4$ \\
\hline week 1 & \multirow{3}{*}{$>32$ Weeks } & $2.70+/-0.6$ & $12.3+/-2.1$ & $2.6+/-1.6$ \\
\hline Week 2 & & $2.05+/-0.4$ & $10.6+/-1.6$ & $2.5+/-1.9$ \\
\hline Week 4 & & $1.66+/-0.2$ & $9.8+/-2.1$ & $1.8+/-0.8$ \\
\hline
\end{tabular}

Figure-1. Normal ranges of thyroid function tests in premature infants ${ }^{14}$

\begin{tabular}{|c|c|c|c|c|}
\hline & \multicolumn{4}{|c|}{ Gestational Age (weeks) } \\
\hline & $<28(n=9)$ & $28-<30(n=59)$ & $30-32(n=33)$ & $>32(n=41)$ \\
\hline TSH (Mean+SD) & $2.31 \pm 0.83$ & $3.72 \pm 2.74$ & $4.11 \pm 1.31$ & $4.31 \pm 2.52$ \\
\hline T4 (Mean_SD) & $5.21 \pm 2.18$ & $6.03 \pm 1.80$ & $7.78 \pm 2.57$ & $7.53 \pm 1.86$ \\
\hline
\end{tabular}

\begin{tabular}{|l|c|c|c|}
\hline & \multicolumn{3}{|c|}{ Study Intervals } \\
\hline & Week 1 & Week-2 & Week-4 \\
\hline TSH $($ Mean \pm SD) & $3.55 \pm 1.91$ & $4.79 \pm 3.02$ & $4.18 \pm 1.84$ \\
\hline Free T4 (Mean+SD) & $1.28 \pm 0.24$ & $1.29 \pm 0.49$ & $1.31 \pm 0.21$ \\
\hline T4 (Mean \pm SD) & $6.35+1.80$ & $6.42+1.79$ & $5.92+1.96$ \\
\hline
\end{tabular}

\begin{tabular}{|l|c|}
\hline \multicolumn{1}{|c|}{ Thyroid Function Disorder } & Number (\%) \\
\hline CHT & $12(8.5 \%)$ \\
\hline Transient Hypothyroxinemia & $65(45.7 \%)$ \\
\hline Transient Hyperthyroxinemia & $12(8.5 \%)$ \\
\hline \multicolumn{2}{|c|}{ Table-III. CHT, Transient hypothyroxinemia and transient hyperthyroxinemia amongst neonates } \\
\hline
\end{tabular}




\begin{tabular}{|c|c|c|c|c|}
\hline Clinical Status & $\begin{array}{l}\text { Thyroid Function } \\
\text { Disorders }(n=89)\end{array}$ & $\begin{array}{l}\text { No Thyroid Function } \\
\text { Disorders }(n=53)\end{array}$ & Total $(n=142)$ & P-Value \\
\hline RDS & $68(76.4 \%)$ & $39(73.6 \%)$ & $107(75.4 \%)$ & 0.706 \\
\hline NCPAP & $68(76.4 \%)$ & $39(73.6 \%)$ & $107(75.4 \%)$ & 0.706 \\
\hline Mechanical Ventilation & $3(3.4 \%)$ & $2(3.8 \%)$ & $5(3.5 \%)$ & 0.900 \\
\hline PDA & 15 (16.9\%) & $12(22.6 \%)$ & 27 (19.0\%) & 0.395 \\
\hline NEC & 5 (5.6\%) & 2 (3.8\%) & 7 (4.9\%) & 0.623 \\
\hline Sepsis & 8 (9.0\%) & 10 (18.9\%) & 18 (12.7\%) & 0.87 \\
\hline
\end{tabular}

\section{DISCUSSION}

Preterm infants are considered to be at increased risk of having thyroid dysfunction. Although, in the last couple of decades, few guidelines have indicated screening regarding $\mathrm{CHT}$ in premature neonates but data still lacks regarding best management and outcome in the longer run. ${ }^{15}$

In the present study, mean gestational age was found to be $31.41 \pm 1.93$ weeks while mean birth weight on $5^{\text {th }}$ day was found to be $1261.53+$ 170.36 grams. These findings are very near to what was found in another study conducted in Iran $^{6}$ when they noted a mean gestational age of $30.51 \pm 2.29$ in premature neonates lined up for evaluation of thyroid function disorders. The same study also found mean birth weight to be very closer to our findings $(1246.90 \pm 193.58$ grams).

In our study, gestational age of most neonates $(52.1 \%)$ were above 30 weeks which is quite similar to Armanian AM et $\mathrm{al}^{6}$ where they noted a mean gestational age of 30.51 weeks but our findings were little different from Chung $\mathrm{HR}$ et $\mathrm{al}^{16}$ where they found that to be 28.5 weeks.

In the current study, we noted transient hypothyroxinemia to be the commonest, found in $52(36.6 \%)$ neonates, transient primary neonatal hypothyroidism in $13(9.2 \%)$, transient hyperthyrotropinemia in 12 (8.4\%) and CHT in 12 $(8.4 \%)$. Chung HR et $\mathrm{al}^{16}$, noted the frequency of $\mathrm{CHT}$ as $12 \%$ while Armanian AM et $\mathrm{al}^{6}$ noted $\mathrm{CHT}$ to be present in $6.34 \%$ preterms. The difference in terms of frequency of $\mathrm{CHT}$ in comparison to the findings of Chung HR et al ${ }^{16}$ could be due to lower mean gestational age found in that study (28.5 weeks). Hashemipour $\mathrm{M}$ et $\mathrm{al}^{17}$ from Iran noted 1 case of $\mathrm{CHT}$ amongst 349 live births but that study included term, preterm, and LBW neonates. Researchers from Belgium have reported incidence of $\mathrm{CHT}$ in premature neonates as 5 to $18 \% .^{18}$

Armanian et $\mathrm{al}^{6}$ found transient hypothyroidism and hyperthyrotropinemia as $8 \%$ and $16 \%$ in preterm neonates while these findings are very near to what we found in the present study. Very similar to our results ${ }^{19}$, others have also noted transient hypothyroxinemia to be the commonest thyroid function disorder amongst preterm neonates. Seriousness of thyroid function disorders have been observed to be disturbed more with decreasing gestational age previously, we also noted that on the whole, thyroid functions improved with the increase of gestational age in neonates..$^{20}$ It has been found in the past that transient hypothyroidism contributes more to neuro-developmental disorders while levethyroxine has been found to save these neonates from most common complications. ${ }^{6}$

In the current study, RDS (75.4\%), PDA (19.0\%), sepsis $(12.7 \%)$ and IVH (5.6\%) were found to be most common clinical status amongst preterm neonates. Chung HR et $\mathrm{al}^{16}{ }^{16}$ noted RDS, IVH, and NEC to be the commonest findings while our results were well aligned to the findings of Armanian AM et $\mathrm{al}^{6}$ where they found RDS and PDA to be the commonest findings amongst preterm neonates. 
Our study is the very $1^{\text {st }}$ one in this region to evaluate preterm neonates for thyroid function disorders but as we had a comparatively shorter sample size along with a slim 6 months follow up, more studies involving multi-centers and longer follow ups could further add to the spectrum of thyroid function disorders in these neonates.

\section{CONCLUSION}

In LBW preterm neonates, thyroid function disorders are quite common. Transient Hypothyroxinemia was noted to be the commonest disorder while RDS, PDA and sepsis were the most seen clinical findings. Thyroid function tests should be done in all premature neonates.

Copyright@ 04 Mar, 2020.

\section{REFERENCES}

1. Chung HR. Screening and management of thyroid dysfunction in preterm infants. Ann Pediatr Endocrinol Metab 2019; 24:15-21.

2. Fanaroff AA, Fanaroff RJ, Martin RJ, Klaus MH, Avroy A. Neonatal-perinatal medicine: Diseases of the fetus and infant. 10th ed. Missouri: Mosby; 2015. 3.

3. Elahi S, Laeeq F, Syed Z, Rizvi SM, Hyder SW. Serum thyroxine and thyroid stimulating hormone levels in maternal circulation and cord blood at the time of delivery. Pak J Med Sci. 2005; 21 (3):325-30.

4. Harris $\mathrm{KB}$, Pass $\mathrm{KA}$. Increase in congenital hypothyroidism in New York State and in the United States. Mol Genet Metab. 2007; 91(3):268-77.

5. Mitchell ML, Hsu HW. Massachusetts Pediatric Endocrine Work Group. Unresolved issues in the wake of newborn screening for congenital hypothyroidism. J Pediatr 2016; 173:228-31.e1.

6. Armanian AM, Kelishadi R, Barekatain B, Salehimehr N, Feizi A. Frequency of thyroid function disorders among a population of very-low-birth-weight premature infants. Iran J Neonat. 2016; 7(3):10-6.

7. Williams FL, Simpson J, Delahunty C, Ogston S, Bongers-Schokking JJ, Murphy N, et al. Developmental trends in cord and postpartum serum thyroid hormones in preterm infants. J Clin Endocrinol Metab. 2004; 89(11):5314-20.

8. Klein AH, Oddie TH, Parslow M, Foley TP Jr, Fisher DA. Developmental changes in pituitary_thyroid function in the human fetus and newborn. Early Hum Dev. 1982; 6(4):321-30.
9. Adams LM, Emery JR, Clark SJ, Carlton EI, Nelson JC. Reference ranges for newer thyroid function tests in premature infants. J Pediatr. 1995; 126(1):122-7.

10. Murphy N, Hume R, Van Toor H, Mattews TG, Ogston SA, Wu SY, et al. The hypothalamic_pituitary_thyroid axis in preterm infants; changes in the first $\mathbf{2 4}$ hours of postnatal life. J Clin Endocrinol Metab. 2004; 89(6):2824-31.

11. Calaciura F, Motta RM, Miscio G, Fichera G, Leonardi $D$, Carta $A$, et al. Subclinical hypothyroidism in early childhood: A frequent outcome of transient neonatal hyperthyrothropinemia. J Clin Endocrinol Metab. 2002; 87(7):3209-14.

12. Fisher DA. Thyroid function and dysfunction in premature infants. Pediatr Endocrinol Rev. 2007; 4(4):317-28.

13. Van Wassenaer AG, Kok JH. Hypothyroxinaemia and thyroid function after preterm birth. Semin Neonatol. 2004; 9(1):3-11.

14. LaFranchi S, Kirkland JL, Garcia-Prats JA, Hoppin AG. Clinical features and detection of congenital hypothyroidism. Waltham, MA: UpToDate; 2009.

15. Léger J, Olivieri A, Donaldson M, Torresani T, Krude $H$, van Vliet $G$, et al. European Society for Paediatric Endocrinology consensus guidelines on screening, diagnosis, and management of congenital hypothyroidism. Horm Res Paediatr 2014; 81:80-103.

16. Chung HR, Shin $\mathrm{CH}$, Yang SW, Choi CW, Kim BI, Kim EK, et al. High incidence of thyroid dysfunction in preterm infants. J Korean Med Sci. 2009; 24(4):627-31.

17. Hashemipour M, Amini M, Iranpour R, Sadri GH, Javaheri N, Haghighi S, et al. Prevalence of congenital hypothyroidism in Isaac, Iran: Results of a survey on 20000 neonates. Horm Res Pediatr. 2004; 62(2):79-83.

18. Rooman RP, Du Caju MV, De Beeck LO, Docx M, Van Reempts P, Van Acker KJ. Low thyroxinaemia occurs in the majority of very preterm newborns. Eur $\mathrm{J}$ Pediatr. 1996; 155(3):211-5.

19. Perlman JM. Neurobehavioral deficits in premature graduates of intensive care potential medical and neonatal environmental risk factors. Pediatrics. 2001; 108(6):1339-48.

20. Gressens P, Rogido M, Paindaveine B, Sola A. The impact of neonatal intensive care practices on the developing brain. J Pediatr. 2002; 140(6):646-53. 


\begin{tabular}{|c|c|c|c|}
\hline \multicolumn{4}{|c|}{ AUTHORSHIP AND CONTRIBUTION DECLARATION } \\
\hline Sr. \# & Author(s) Full Name & Contribution to the paper & Author(s) Signature \\
\hline 1 & Abdur Rehman & $\begin{array}{l}\text { Introduction, Discussion, } \\
\text { Resutls, Final approval. }\end{array}$ & Hearluan \\
\hline 3 & Ahmed Iqbal Quddusi & $\begin{array}{l}\text { Resutls, Final approval. } \\
\text { Introduction, Resutls, } \\
\text { Discussion. }\end{array}$ & AQudelusi \\
\hline 4 & Ashee Nadeem & $\begin{array}{l}\text { Introduction, Resutls, } \\
\text { Discussion. }\end{array}$ & $d^{x}$ \\
\hline 5 & Imran Iqbal & $\begin{array}{l}\text { Introduction, Resutls, } \\
\text { Discussion. }\end{array}$ & de \\
\hline
\end{tabular}

